\title{
Fine Structure of the Low-Frequency Raman Phonon Bands of Single-Wall Carbon Nanotubes
}

\author{
M. N. Iliev and A. P. Litrinchuk \\ Texas Center for Superonduclicity ard Department of Physics, \\ Eniversity of Houston. Houston. TX 79:014-5092 \\ S. Arepalli and P. Nikolaev

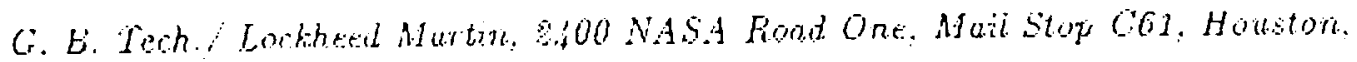 \\ ') $X 70.59$ \\ C. D. Scott \\ N.4SA Johnson Srowe Certer, Hoistom, TX $77058-9696$
}

\begin{abstract}
The Raman spectre of single-wall carbon nanotubes (SWNT! produced by laser and arc process were studird between 5 aud $500 \mathrm{~K}$. The line width visuperature dependeuce of the low-frequency Raman bards betwen 150 and $200 \mathrm{~cm}^{-1}$ deviates from that expected for phonon decay though phonom-phonon scattering inectanism. The oxperinental resulte and their analy is prowde convineng evidence that each of the low-frequency Ramet lines is a superposition of several narrower Raman lines corresponding to tubes of nearly the same diameter. The application of Raman spectroscopy to probo the distribution of SWN'L by both diameter and chirality is discusscd.
\end{abstract}

\section{Introduction}

The Raman spectra of carbon nanotubes, in particular single-wall nanotubes (SWNT). have ben arudied intensively, both experimentally $|1-7|$ and theoretically [8 13$]$. It has been established that the Raman interisitios of the high-frequency ragential $11500-1600 \mathrm{~cm}^{-1}$; and low-frequency radial (140)$250 \mathrm{~cm}{ }^{1}$ i modes eitibit strongly resonant behavior [3-5]. 11. was also fourd that the frequency wh of the zone-center in-phasc radial "breathing" i mode is inversely proportional to the radius of the tube and is either independent $[5,13]$ or negligibly dependert $[1$ l] on the diral angle. Assuming that a SWNT 
sample is a mixture of achiral and chiral nanotubes of different diameter, the Ramin spectum will be a superposition of spectra of all types of tubes in the scattering wolume, the relative weight being deterwined by their aburdarce and Raman cross section. The existence of several peaks in the spectra betwen 140 and $250 \mathrm{~cm}^{-2}$ is therefore an evidence of tubes with various diarreters betwen 1.1 and $2.0 \mathrm{~nm}$, in agrement with the results of scanning electron microscopy (StM) and $x-1$ ay aralysis $(3,14]$. The issue is whether the observed Raman lines are inhomogeneously brodened complex bands consistine of several overlapping simple lines of close wave numbers (diameters) or simple homogenous bands

In this work we report the variations with temperature of the Raman spectra of SWNT in the temperature range betwen $5 \mathrm{~K}$ and $500 \mathrm{~K}$. In particular we studied in detail the betavior of the weil resolved peak near $165 \mathrm{~cm}^{-1}$ (at $300 \mathrm{~K}$ ): corresponding to the radial in-phase-vibration mode of tubes of diasueter close to $1.36 \mathrm{~nm}$. While the temperature dependence of the line width for the latter peati is inconsistent with the expectations for an anharmonic decay of a single phonon through phonom-phonon scattering: the experimental data can satisfactorily be explained within such a mechanism by considering the $165 \mathrm{~cm}^{-1}$ band as a superposition of several closely lying components.

\section{Samples and Experimental}

The SWNT samples were obtained by are awd ber producrion methods. The are method is similar to that descobed in Pef. $15 \mid$ using a $20 \mathrm{~cm}$ water cooled inner cylinder located inside a 30 cri chanber. The run conditions were: 35 volts; 100 anp s; 100 scom tow of helium at 66.7 kPa 1500 Torr). Fart of like collaterte deposit on the cathode was used for making "a "bucky paper" (folt-like) sauple for chatracterization. The laser method is described in. Ref.[16] and is a two-laser oven method used originally by Smalley's group at Rice Univereity. The rum conditions were green litser pulse $(300 \mathrm{~m} ., 5 \mathrm{~mm}$ dianetery followed by IFi laser pulse $(300 \mathrm{~mJ}$, $5 \mathrm{~mm}$ dianeter) after $50 \mathrm{nscc} ; 5 \mathrm{~cm}$ quartz How tube in an oven at $1473 \mathrm{~K}$ with 100 scom argon flow at $66.7 \mathrm{kPa}$ (500 Torr. Carbon soot containing Ininotubes deyosited on the walls of the quartz tube was used for making bucky paper as follows. The material (10 mer was sonicaled in acetone and filcered though a teflon membrane filter (25) mm diameter, $5 \mu \mathrm{m}$ pore size; Mitex; undar vacuum. The dried bucky papor removed fron the lilter paper was used for tharacteri\%ation studjes.

The Rarnan spectra were measured using the He-Ne laser line $(6.32 .8 \mathrm{~nm})$ and a single spectrometer $(1800 \mathrm{gr} / \mathrm{mm}$ grating coscope $(\times 50$ objective!, a notch filter and a hquid-ritrogen-cooled chargecoupled device (COD) detector with $15 \times 15 \mu \mathrm{m}$ pixel sjec The spertral reso- 
lution was $13 \mathrm{~cm}^{-1}$ as evidenced by che width of the laser plasma lines. The samples $\left(2 \times 2\right.$ mon in size) were mounted in a Microstat ${ }^{H e}$ cryostat (Oxford Instrument.). where (he temperature could be varied between 5 and $500 \mathrm{~K}$. To minimize local laser henting the laser power in the focus spot of $5-7 \mu \mathrm{m}$ diameter was kept below $0.5 \mathrm{~mW}$, which corresponds to average laser power density of $1000-200011 . \mathrm{cm}^{-2}$. Further reduction of the laser power had no effect on the spectral line shape. Spectra taken from different spots on the surface of the sarne sample were practically identical, a fact which indicates the homogeneity of the samples studied.

\section{Results and Discussion}

Fig. 1 shows the low-frequency and high-frequency parts of the Raman spectra of SWNT as obtained at $10 \mathrm{~K}$ from the three different. samples used in our expcriments: Sample N1, prepared by laser process [16], Sample N2, prepared by arc process [15], and Samplo N4. prepared by laser process at the same conditions as Sample N1 but using a different laser vaporization target and subsequently puritied, following the procedure described in Ref [3]. As it follows from Fig. 1 the spectra of Sample N1 and Sample N2 are very similar and exhibit well ponounced maxima at $167,154-185,190-192$, and $195 \mathrm{~cm}^{-1}$ in the region of radial $A_{1 g}$ (or A) phonon modes. They conespond to tube diamtere of $1.35,1.22 .1 .17-1.18$, and $1.15 \mathrm{~mm}$, respectively. In the high-frequency region between 1200 and $1800 \mathrm{~cm}^{-1}$ the spoctra of Samples $\mathrm{N} 1$ and $\mathrm{N} 2$ extubit. peaks at $1321.1549,1589,1602$, and $1754 \mathrm{~cm}^{1}$ iat room lemperature these peaks are at $1321,1546,1589,1598$ and 1747 cm 1 . Followivg the aualysis of Kasuya et al. [2] the complex structure of the $1540-1600 \mathrm{~cm}^{-1}$ band can be understood by zone-folding of the graphite phonon dispersion relations the relative intensity of the broad peak at $1324 \mathrm{~cm}^{-1}$ is higher for Sample $\mathrm{N} 2$. The origin of this peak is not well understood. Its position has been found to vary strongly with the laser excitation wavelength [1] from $1258 \mathrm{~cm}^{-1}$ with $1320 \mathrm{~nm}$ excitation to $134 \mathrm{im}^{-1}$ with $5145 \mathrm{~nm}$ and its appearance has tentatively been assigned to a symmetry-lowering effect, such as defects of nanotube caps, bending of the nanotube, or the presence of nanoparticles and amorphous carbon. [17] The peak at $1754 \mathrm{~cm}^{1}$ has been attributed ro second-order Rarman processes involving combinations of radial and tangential modes [7]

The spectra [rom Sample NA differ significanty from these of Samples N1 and N2. The low-freguency peaks at 173.181 and $195 \mathrm{~cm}^{-1}$, correspond to bataina. in the tube diameter distribution of $1.30,1.24$ and $1.1 .5 \mathrm{~nm}$, respectively Since the haman spectra of all samples have been taken at the same experimental conditions, the distppearance of the peak at $16 \mathrm{~cm} \mathrm{~cm}^{-1}$ and the appearance of the $173 \mathrm{~cm}^{-1}$ peat cannot be attributed to changes of the resonant con- 
ditions and indicates that the average dianeter of the tubes in Sample NA is smaller. The high-frequency peaks in the Fanaln spectrum of Sample N4 are also shifted towards higher wave numbers: at $1336,1585,1608,1622$ and $1768 \mathrm{~cm}^{-1}$, respectively (at room temperature the pronounced maxima are at $1328,1564,1589,1609$, and $\left.1763 \mathrm{~cm}^{-1}\right)$

The Pannaj! spectra of SWNT exhibit relatively weak charges with temperature. Further we will concentrate on the variations with temperature of the low-frequency part of the spectra as illustrated on Fig.2 for Sample N2. The spertra of Sample N1 and Sample N1 vary in a similar woy 'The spectral line shapes of Fig 2 can be fitted by five Lorentzians and an eren better fit is obtajed by curves of mixed Larentzian-Gaussiar profiles. As expected. the main effect of increasing the temperature is a shift cowards lower wave numbers and broadening as shown in Fig.3 for the well seprated peak uear $16 \mathrm{~cm}^{-1}$. In the case of simple phonon lines the line width is a measure of the phoron lifelime. It is determined by the dominating scattering mechaniso. which could be tempcrature-independerl / scallerirg from lanice defects or tomperaturedependent scattering from phonons!. Following the standard model for anharmonic phonon decay through phonon-phonon scattering. proved to be valid for most crystalline materials $[18,19]$, the varitions of phonon line width with teruperature $r(1)$ follows the dependence:

$$
\Gamma(T)=\Gamma_{0}\left(1+\frac{2}{e^{x}-1}\right)
$$

where is the temperature-independent pat of the line width, $x=$ hiw $\left(2 k_{B} T\right)$, $F_{w}$ is the phonon energs, $k_{E}$ is the Bolczman constant. Thovided the $167 \mathrm{~cm}^{-1}$ line corresponds to a single hom ogenous line ane expects from Eq.(1) (for $\gamma=0$ ) an increase of its width upon varying the temperature from $10 \mathrm{~K}$ to $500 \mathrm{~K}$ by a factor of 8.1 . As it is seen from Fig. 3 this is obviously not the case This implies that a more realistio approach. which assumes contribution of several close lying homogeneous lines, je required to describe the observed temperatule erolution of the band width

We modeled the band at $167 \mathrm{~cm}^{\cdots 1}$ as a superposition of four close lving Lorentzian components with the naxima $w_{0}$ it 168.1 . 167.2, 164. $\overline{\text { ind }} 167.5$ $\mathrm{m}^{-1}$ These positions obtained from the expression:

$$
\therefore(m, n)=\frac{223.75}{\left.d_{1+1, m}\right)}=\frac{\pi 22375}{d a-a \sqrt{3} \sqrt{n^{2}+m^{2}+n n}}=\frac{2856}{\sqrt{n^{2}+m^{2}+n m}}
$$

are the closost ones to $16 \mathrm{icm}^{-1}$ and correspond to lubes of chiral indices (mu) of $(17,0),(16,2), 15.4)$ and $(14,5)$. respectively. In Eqs $(2): 22.3 .55 \mathrm{~nm}^{-1} \mathrm{~cm}^{-1}$ is the experimentally determined "universt" constant [5]. and $d_{0-0}=0.142 \mathrm{~nm}$ 
(11,9) and $163.9 \mathrm{~cm}^{-1}(12,8)$, or the replacement of any of the four components by another one at a close position does not affect signiticantly the results described below.

The fit of the experinantal spetrum for $\mathrm{T}=10 \mathrm{~K}$ wis achieved by varing the intensities of the components for fixed wo and given" and $\Gamma_{0}$. The firmal resolution of the experimental setup was also raten into account by convoluting the calculated spectrum with the instrunental function. As it is sem from Fig. 4 (lower curbe), it was possible to reproduce reasonatily vell the experimental line shape at lou temperature. Further. 10 estimate the terperature dependence of the lincwilth. We perfomed a series of simulations assumings that $\Gamma(T)$ of each of the components follows the dependence ili. The results of wodel calculations are sumnarized in tig. a by solid lines. As it is clatrly seen, one can successfully describe the experimentally observed behavior of the band width within the whole temperature range between 0 and $500 \mathrm{~K}$ for $y \approx 2.0 \mathrm{~cm}^{-1}$ and $\Gamma_{0} \approx 1.0 \mathrm{~cm}^{-1}$. Using these values and accounting for the temperature induced froquency softening by shifing all wo by the same ancint towards lower wave numbers, onc can fit the experimental spectra at higher eruperatures, as illustrated in Fig. 4 luppor curve for $\mathrm{T}=500 \mathrm{~K}$.

The results presenced abore show that the Raman spectoscopy may becone an effoient tool for charactecization of SWNL for tube diameter distribution. Frovided the Raman cross section vs tube dianeter dependence for a given laser excitation energy (wavelength) is known, the nomalized experimental spectrum will represent the distribution of thbes by diameter. The nomalized spectrum could then be modelled as a superposition of all lines with isfm,ni within the frequency range thus determining the teldive weight of the corresponding (m.n) tubes in the sample.

\section{Acknowledgments}

Wo thank A M. Fino, F'. Eklude and V. G. IIadjey for useful discussions 'This work was supported in part by the State of Texas through the lexas Center for Superconductivity at the University of Houston and by NASA contract NASA-19100. 
Fig. 1. Raman spectra al 10 K of three different SWNT samples.

Fig. 2. Variation with temperature between 10 and $500 \mathrm{~K}$ of the Raman spectra of Sample N2 (arc process). The spectral resolution is $1.3 \mathrm{~cm}^{-1}$.

..

Fig. 3. Experimental (points) and calculated (curves) rempcrature dependence of the width of the $167 \mathrm{~cm}^{-1}$ band. The band is simulated a consisting of four close Jyiug Lorentzian coupononts with $y=2.9 \mathrm{~cm}^{-1}$ and $\left[l^{1} \theta=0.5 .1 .0\right.$, and $1.5 \mathrm{~cm}^{-1}$.

Fig. 7. Experiumental (points) and culculated (curres) protiles of the $167 \mathrm{~cm}^{-1}$ band of 5 ample $\mathrm{N}^{2}$ at. $10 \mathrm{~K}$ (lower curve a d $500 \mathrm{~K}$ (upper cureel. The foting parameters are $\because=2.2 \mathrm{~cm}^{-1}$ and $\mathrm{ro}=0.9 \mathrm{~cm}^{-1}$.

\section{References}

(1) A. M. Rao, E. Richter, S. Bandow. B. Chace, P. C. Eklund. K. A. Williams S. Fang, K. K Subbawam M. Menom A. Thess. R. E Smalleg. (G. Tresoelhaus, and M. S. Tresselhans, Sicience 275 (1997) $18 T$.

(2) A. Kanya Y. Sasaki. Y. Saito, K. Tohij, and Y. Nishina. Fhys. Rev. Lett. Ts (1997) 4434.

[ï] A. C. Kindzler, J. Lin, H. Dai, P. Nibolaev, C. B. Hothman, F. J. RodriquezMacias. P. J. Boul. A. H. Lu, D. Heymaun. D. T. Coltort. R. S. Tee J. E. Fischer, A. M. Rau, P. C. Elluud, and P. E. Smalley Appl. Pbys A 67 (1993) 29. 


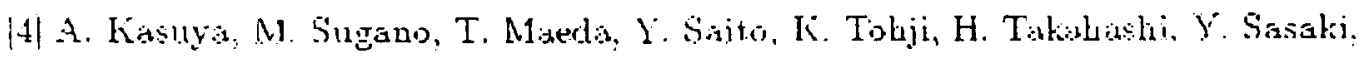
M. Fukushima. Y. Nishina, and $C$. Hurie, Pbys Rev B 57 (1996) 4969.

[5] S. Bandow, S. Asaka, Y. Saito, A. M. Rao, L. Grigorian, F. Ricuter, aud P. C. Eklund, Phys. hev. Ler. 80 (1998) $37 \% 9$.

[6] F. Huang. K. T. Yue, P. Jar, S.T. Zhang, Z. Shi, X. Zhou, and Zh. Gu. J. Appl. Fhys 84 (1993) 4022.

[7) M. A. Pimeuld A. Maruci, S. A. Fimpedacles, M. C. Earendi. E. B. Hanlon,

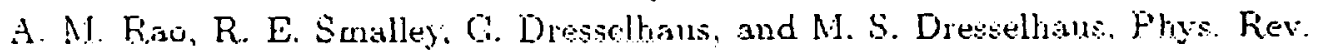
B $5 S$ (1993) R.16016.

(9) R. A. Jisbi, L. Ventataraman. M. S. Dreselbaus and G. Dresseltatus. Chem. Pliys. I_ett. 209 (1993i ir.

(9) R. Saito, T. Takeva, T. Kimura. G. Dresselhans and M. S. Dhesselbaus, Phys. Piev. B 5 r $(1998)+145$.

110| A. Chalier, E. MCRae, M.-F. Cbarlier: A. Spire and S. Forster, Pbre Kev. B 57 i $1998 ; 6689$.

[11] J. Küti, G. Kresce and H. Kuzwany: Phys Ker. B 58 (1998) F8869.

[12] R. Silci. T. Takeya, T. Kimnta G. Dresselbaus and M. S. Dresseltaus, Phys. Rex. 559 (1999; 2389.

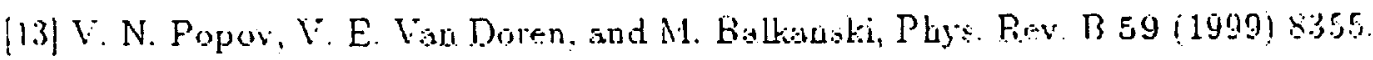

$\mid 14\}$ A. Thesa. R. Lee. P. Nikolare. H. Tai, F. Petit, J. Rotert. C. Hu, Y. H. Lee. S. G. Kirn, A. G. Rinzler, D. T. Colbert. G. E. Scuscria, D. Tombrek, J. E. Fischer, and R. E. Sulalloy: Science 273 (1996) 490.

[15] C. Journet, W. K. Maser, P. Bernier, A. Loisen. M. Iamy de la Cbapelle, S. Tefrant. P. Deniard, R. Lee, and J. E. Fisher, Nature 385 (1997) 756.

(16) T. Guo, F. Nikolaev. A. Thess. D. T. Colbert, and R. E. Bmalloy, Chem. Phys. Lett. $243(1995) 4 !$

[1.7) R. Saito, C. Lresselbans, ard M. S. Dresselbans, "Physial Fropertics of Carbon. Namotahes" (Imperial Collego Press, London, 1998).

[18| I. F. Ipatora, A. A. Maradudin, and R. F. Walls, Phys Rev. 155 (1967) 802

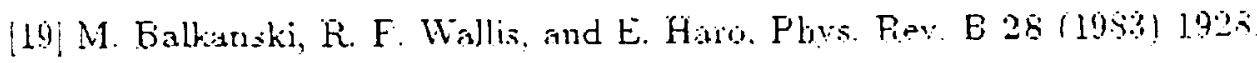




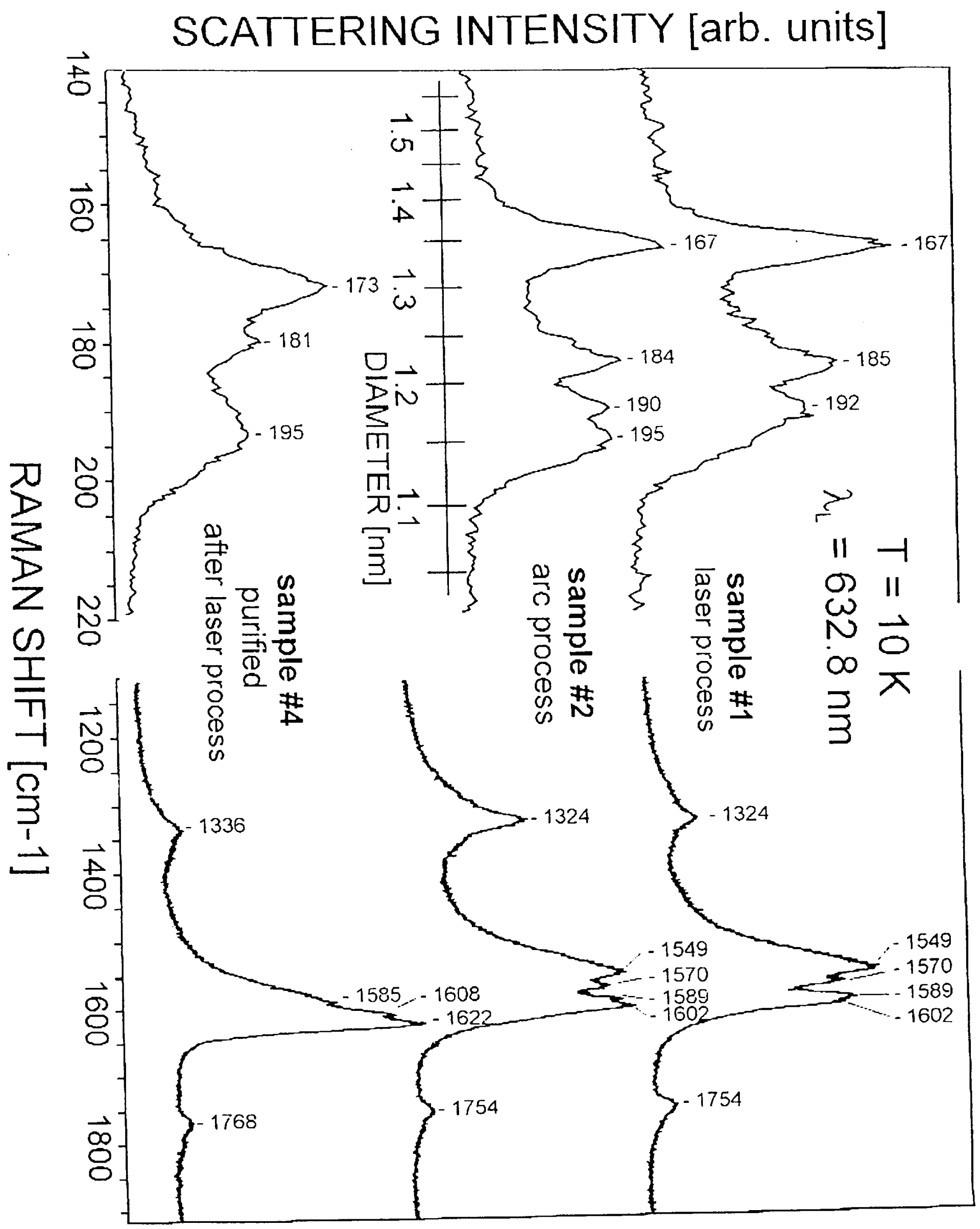




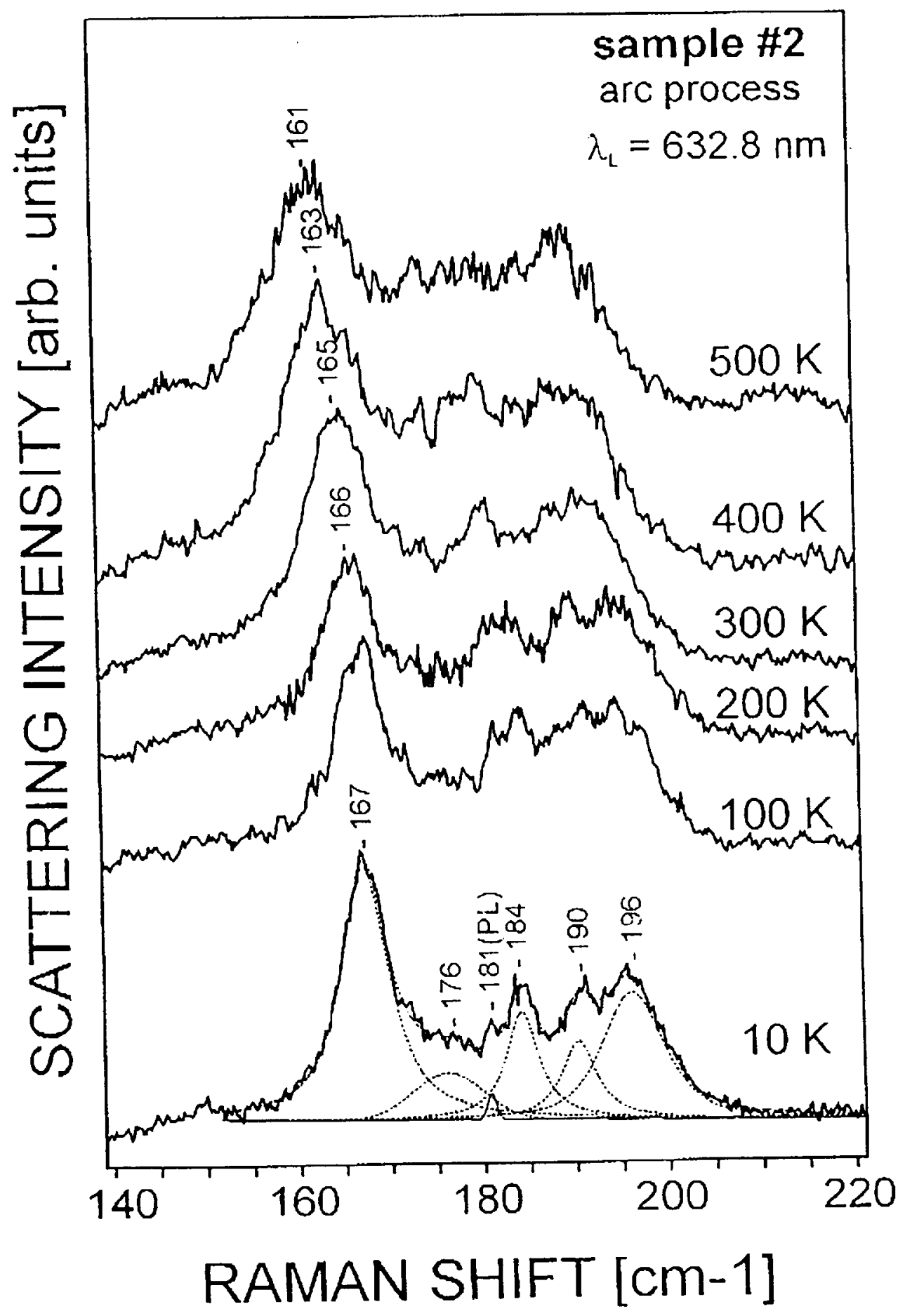




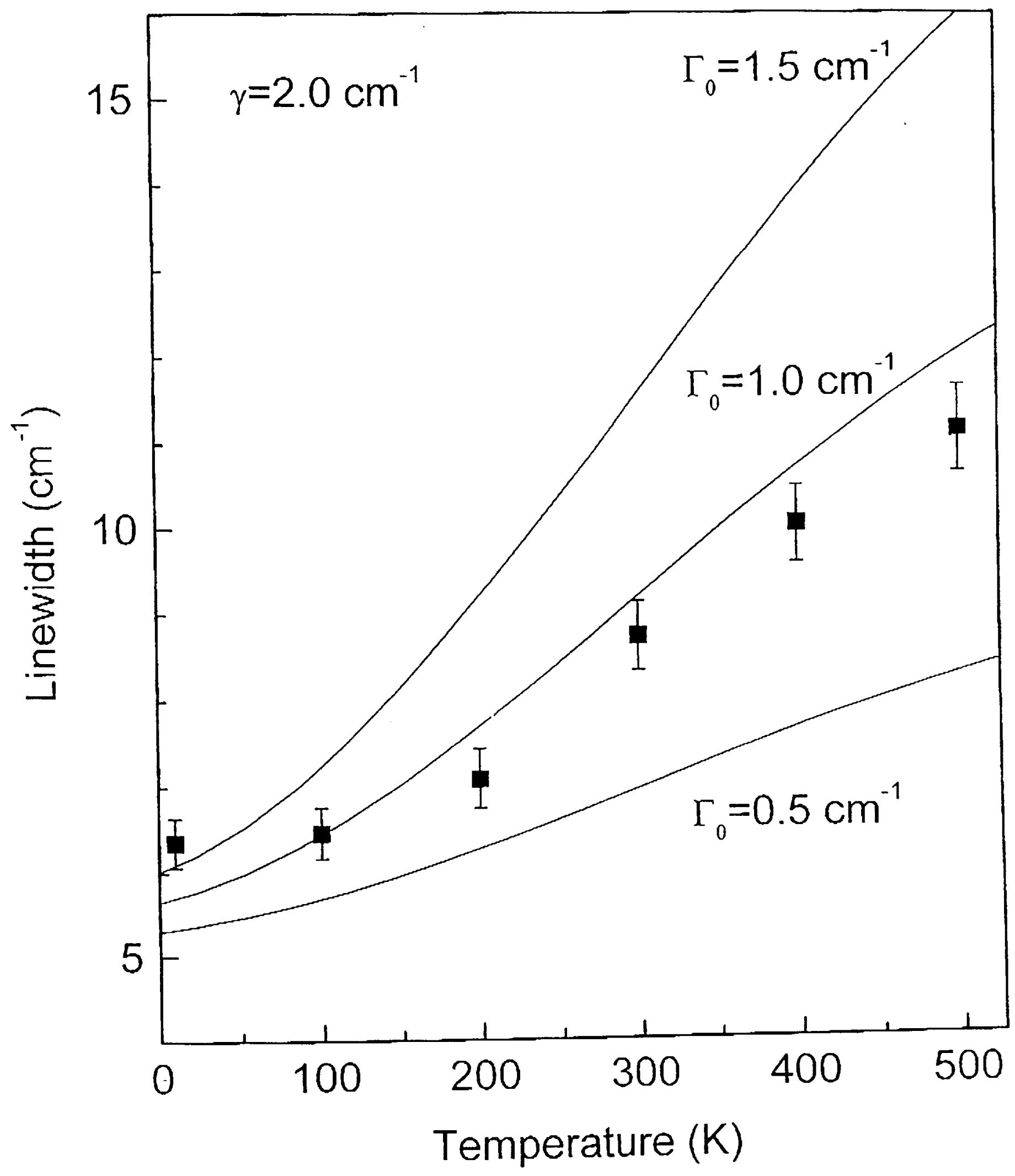

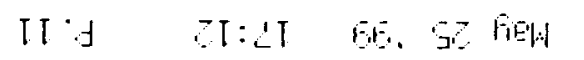




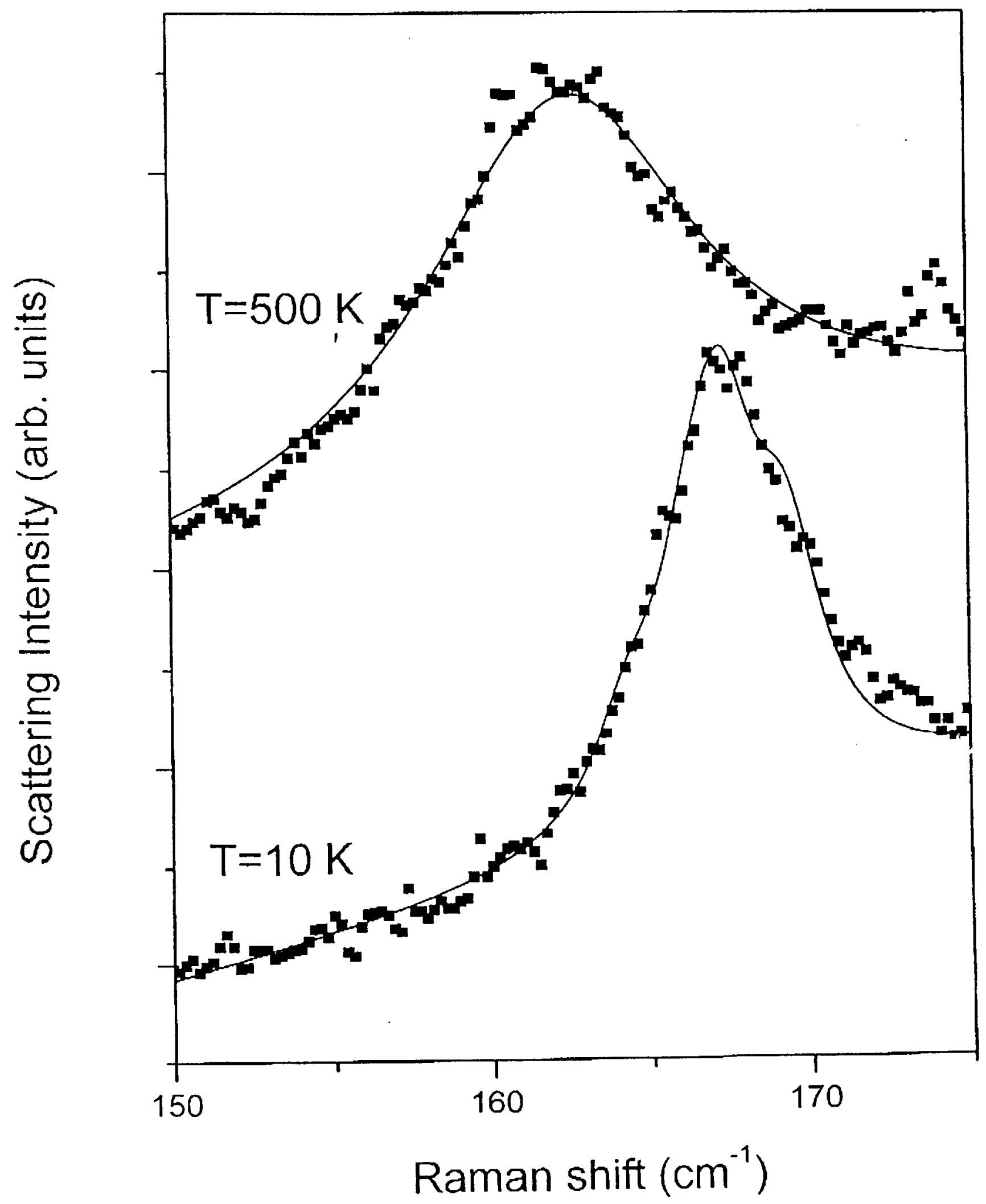

